\title{
Atrial myxoma presenting with cerebral haemorrhage
}

\author{
V.M. Macaulay, P.J. Crawford and R.O. McKeran
}

Departments of Neurology and Neurosurgery, Atkinson Morley's Hospital, Copse Hill, Wimbledon, London, S.W.20, UK.

\begin{abstract}
Summary: Emboli from left atrial myxomas are a recognized cause of cerebral ischaemia. The myxomatous embolus may infiltrate the cerebral arterial wall, resulting in aneurysmal dilatation with a risk of rupture. Myxoma-associated cerebral haemorrhage has been described in patients with progressive neurological dysfunction. We report a new presentation. Our patient, a previously healthy 20 year old girl, developed acute intracerebral haemorrhage for which craniotomy was performed. Histology of evacuated haematoma revealed an intravascular fragment of myxoma. Echocardiography demonstrated a left atrial myxoma which later was uneventfully excised. Early diagnosis of embolic cardiac myxoma requires awareness of the diversity of clinical manifestations, and careful histological analysis of surgical specimens.
\end{abstract}

\section{Introduction}

Left atrial myxomas present with cardiac dysfunction, systemic features or emboli of thrombus or myxomatous tissue (Silverman et al., 1962). Fifty percent of emboli involve the central nervous system (Silverman et al., 1962), producing transient ischaemic attacks and infarcts. Initial presentation with acute cerebral haemorrhage has not previously been recognized.

\section{Case report}

A 20 year old right-handed girl, born in Britain of Jamaican parents, was previously healthy apart from episodic crops of red, tender spots on the skin of the hands and feet.

She was admitted to another hospital with a $36 \mathrm{~h}$ history of headache, drowsiness and difficulty in speaking. She was febrile with signs of meningism. Lumbar puncture yielded blood-stained cerebrospinal fluid (CSF) with an opening pressure of $17 \mathrm{~cm}$ of water, red cell count $15.04 \times 10^{9} / 1$, white cell count $52 \times 10^{6} / 1$ (mainly polymorphs) and protein $4.5 \mathrm{~g} / \mathrm{l}$. The CSF glucose was normal and no organisms were seen on Gram stain. The following day she was incontinent of urine, was noted to be dysphasic and was transferred to this hospital.

V.M. Macaulay, B.Sc., M.R.C.P.; P.J. Crawford, B.Sc., F.R.C.S.; R.O. McKeran, M.Sc., M.R.C.P., M.D.

Correspondence: V. Macaulay, St George's Hospital, Blackshaw Road, Tooting, London SW17.

Accepted: 20 June 1984
On examination she had a global dysphasia, right upper motor neurone facial weakness and a moderate right hemiparesis. The pulse was regular at 85 beats/ min and the blood pressure was $130 / 75 \mathrm{~mm} \mathrm{Hg}$. A soft ejection systolic murmur was heard, with no cranial or carotid bruits. There were no stigmata of bacterial endocarditis.

Routine haematological and biochemical investigations, chest X-ray and ECG were all within normal limits. The ESR was $36 \mathrm{~mm} / \mathrm{h}$, immunoglobulins were normal and blood cultures sterile. Computerized

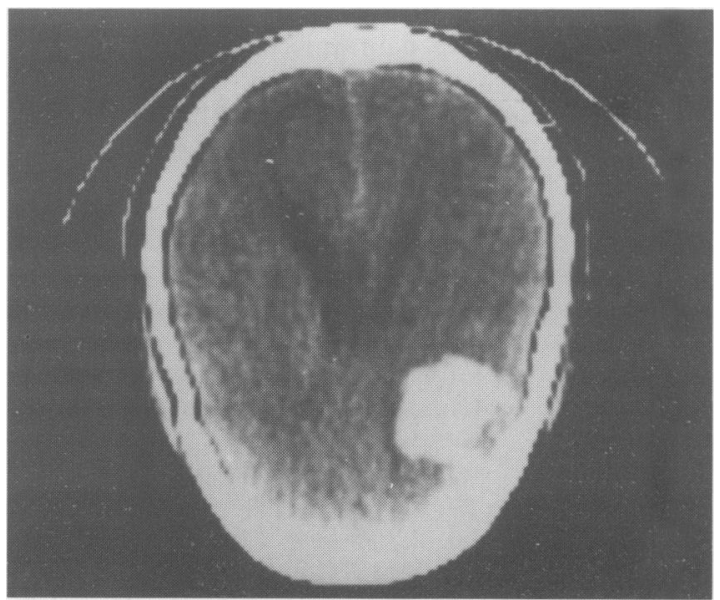

Figure 1 CT scan of brain showing left frontal haematoma.

(C) The Fellowship of Postgraduate Medicine, 1985 
tomography of the brain revealed a left frontal haematoma (Figure 1). Left carotid arteriography showed displacement of vessels around the avascular mass of haematoma, with ectasia of an ascending fronto-parietal branch of the left middle cerebral artery.

Craniotomy was performed and an intracerebral haematoma was evacuated, together with what seemed to be a thrombosed angioma. The patient recovered without complication, and one month later she was asymptomatic with no abnormal neurological signs.

Histology of the surgical specimen showed fragments of brain tissue with arteriovenous malformation and haemorrhage (Figure 2). One of the vascular channels contained a polypoid structure with a myxomatous stroma, thought to represent organized thrombus. But since it could be a myxoma embolus, further cardiological studies were performed.

Echocardiography demonstrated typical features of a left atrial myxoma. At cardiac surgery a friable atrial myxoma was excised. The patient recovered uneventfully.

\section{Discussion}

Cerebral ischaemia is a recognized complication of left atrial myxoma (Silverman et al., 1962). Myxomatous emboli have been shown (Price et al., 1970) to invade the cerebral arterial wall. Local sequelae include stenosis, dilatation and aneurysm formation. These defects are usually multiple, producing characteristic radiological changes. Serial arteriography has revealed progressive aneurysmal enlargement (Roeltgen et al., 1981). Cerebral haemorrhage has been recorded in 4 cases, (Price et al., 1970;; Roeltgen et al., 1981; Steinmetz et al., 1973; Frank et al., 1979), all presenting with progressive neurological disturbance. One patient (Roeltgen et al., 1981) had previously undergone cardiac surgery for myxoma, and in 2 (Price et al., 1970; Steinmetz et al., 1973) the cardiac tumour was not detected in life.

This is the first report of acute intracerebral

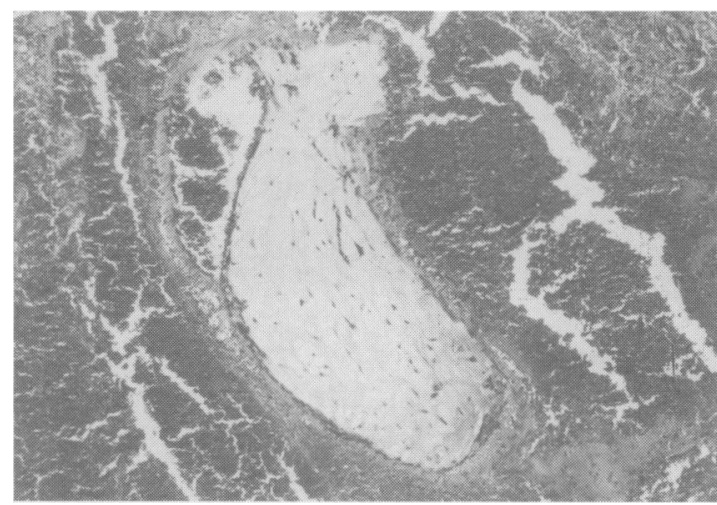

Figure 2 Histological section showing a fragment of myxoma in a cerebral vessel surrounded by haemorrhage. (H. \& E., $\times 80)$.

haemorrhage as the primary presentation of left atrial myxoma. The importance of histological examination of evacuated material is stressed (Maroon \& Campbell 1969), and was diagnostic in our case, revealing a fragment of myxoma within one of several abnormal vascular channels. These may represent ectasia secondary to infiltrating myxoma, although this was not specifically identified. Alternatively, it is possible that differential bloodflow carried the myxomatous embolus into a pre-existing arteriovenous malforma tion, which then bled.

Diagnostic delay in this situation allows further potentially serious manifestations to occur. Atrial myxoma should therefore be considered not only as a cause of cerebral ischaemia or of late bleeding in known cases of myxoma, but also in apparently spontaneous cerebral haemorrhage.

\section{Acknowledgements}

We thank Mr A.E. Richardson and Mr D.J. Parker for permission to report this case. For help with the histological and radiological aspects of the case we are grateful to Professor M.J. Davies and Dr G. Hart respectively.

\section{References}

FRANK, R.A., SHALEN, P.R., HARVEY, D.G., BERG, L., FERGUSON, T.B. \& SCHWARTZ, H.G. (1979). Atrial myxoma with intellectual decline and cerebral growths on CT scan. Annals of Neurology, 5, 396.

MAROON, J.C. \& CAMPBELL, R.L. (1969). Atrial myxoma: a treatable cause of stroke. Journal of Neurology, Neurosurgery and Psychiatry, 32, 129.

PRICE, D.L., HARRIS, J.L., NEW, P.F.J. \& CANTU, R.C. (1970). Cardiac myxoma: a clinicopathologic and angiographic study. Archives of Neurology, 23, 558.

ROELTGEN, D.P., WEIMER, G.R. \& PATTERSON, L.F. (1981). Delayed neurologic complications of left atrial myxoma. Neurology ( $\mathrm{Ny}), 31,8$.

SILVERMAN, J., OLWIN, J.S. \& GRAETTINGER, J.S. (1962). Cardiac myxomas with systemic embolisation. Circulation, 26, 99.

STEINMETZ, E.F., CALANCHINI, P.R. \& AGUILAR, M.J. (1973). Left atrial myxoma as a neurological problem. Stroke, 4, 451. 